\title{
Initial Experiences with Small Group Discussions in MOOCs
}

\author{
Seongtaek Lim, Derrick Coetzee, Björn Hartmann, Armando Fox, and Marti A. Hearst \\ University of California, Berkeley \\ $\{$ stlim, dcoetzee, bjoern, fox, hearst $\} @$ berkeley.edu
}

\begin{abstract}
Peer learning, in which students discuss questions in small groups, has been widely reported to improve learning outcomes in traditional classroom settings. Classroom-based peer learning relies on students being in the same place at the same time to form peer discussion groups, but this is rarely true for online students in MOOCs. We built a software tool that facilitates chat-based peer learning in MOOCs by 1) automatically forming ad-hoc discussion groups and 2) scaffolding the interactions between students in these groups. We report on a pilot deployment of this tool; post-use surveys administered to participants show that the tool was positively received and support the feasibility of synchronous online collaborative learning in MOOCs.
\end{abstract}

\section{Author Keywords}

Peer learning; massive open online courses (MOOCs); chat

\section{ACM Classification Keywords}

H.5.3. Information Interfaces and Presentation (e.g. HCI): Group and Organization Interfaces

\section{INTRODUCTION}

MOOCs are online courses with open enrollment that typically have thousands of active students. They have attracted so many students in part because they offer courses free of charge and in part because they allow students to take the courses on their own schedule and from any location. However, MOOCs currently assume that students work in isolation, which may contribute to high attrition rates.

To improve the learning experience, we are exploring the introduction of peer learning, also known as collaborative learning and cooperative learning, into MOOCs. In peer learning, students work together in small groups to enhance their own and one another's learning. Peer learning in the physical classroom consists of activities in which students form small groups to discuss conceptual questions and to engage in problem-solving. Literally hundreds of research studies and several meta-analyses show the significant pedagogical benefit of peer learning including improved critical thinking skills, retention of learned information, interest in subject matter, and class morale $[2,4,5,7,6,1]$.

Permission to make digital or hard copies of part or all of this work for personal or classroom use is granted without fee provided that copies are not made or distributed for profit or commercial advantage and that copies bear this notice and the full citation on the first page. Copyrights for third-party components of this work must be honored. For all other uses, contact the Owner/Author.

Copyright is held by the owner/author(s).

L@S'14, March 4-5, 2014, Atlanta, GA.

ACM 978-1-4503-2669-8/14/03.

http://dx.doi.org/10.1145/2556325.2567854

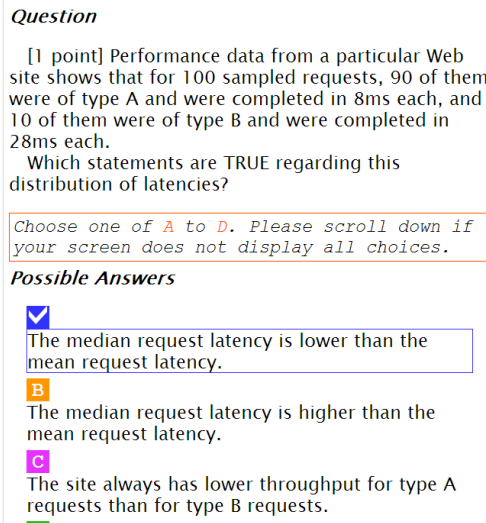

Question

[1 point] Performance data from a particular Web site shows that for 100 sampled requests, 90 of them were of type $A$ and were completed in $8 \mathrm{~ms}$ each, and 10 of them were of type B and were completed in

$28 \mathrm{~ms}$ each.

Which statements are TRUE regarding this distribution of latencies?

Choose one of A to D. Please scroll down if your screen does not display all choices.

Possible Answers

$\checkmark$

The median request latency is lower than the mean request latency.

B

The median request latency is higher than the mean request latency.

C

The site always has lower throughput for type A requests than for type B requests.

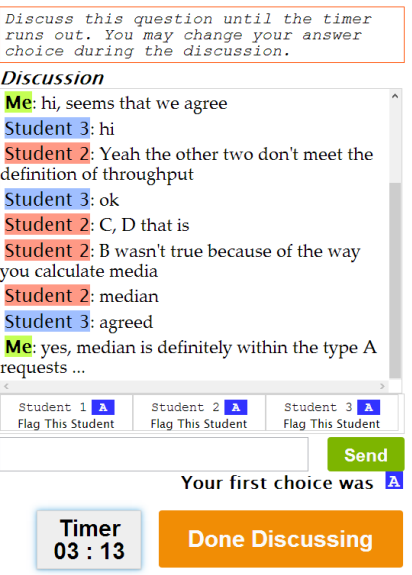

Figure 1. The chat system UI. Upper left: question, lower left: multiple choice answers. The active student chose choice $A$, in blue. Upper right: three students discuss the question in a chat; the other students' choices are shown below the chat; lower right: the remaining time along with a button allowing students to end discussion.

It is not obvious that these results will transfer to the massive, online setting of MOOCs. First, MOOCs lack the physical co-location of classrooms. Second, when peer learning has been transferred to online courses in the Computer Supported Collaborative Learning literature, it has usually been in the context of smaller courses in which the instructor knows the students and the students know one another.

Student interaction is lacking in MOOCs because students are neither collocated, nor are they progressing through course materials on the same schedule. That is, they are distributed in both space and time. Walter's Social Information Processing Theory of Computer Mediated Communication (CMC) argues that communicators deploy whatever cues they have at their disposal [8], which suggests that even a simple text chat may be a reasonable tool for supporting discussion of remote students. To bring students together into synchronous (real-time) groups, approaches from team formation in multi-player games and real-time crowdsourcing [3] can be adapted. In our pilot work, we announce discussion sessions that begin at regular intervals and then form ad hoc groups from the students who are signed on and present at the planned start time.

\section{METHOD}

We set up a testbed for synchronous online discussion which organizes students into groups, allowing them to first individually answer questions and then see each others' answers and discuss those answers, while a timer counts down. When the time is up, the students choose their final answer and are 


\begin{tabular}{lccc} 
Survey Question & A/SA & N & D/SD \\
\hline Helpfulness of Discussion for Final Choice & 11 & 2 & 3 \\
I Was Able to Help Others Learn & 9 & 4 & 3 \\
Others Students Helped Me Learn & 9 & 4 & 3 \\
I Liked Discussing Questions in a Small Group & 14 & 1 & 1
\end{tabular}

and Would Like to Do So Again

Table 1. Survey Responses. A/SA = Agree/Strongly Agree (or Helpful/Very Helpful); N = Neutral, D/SD = Disagree or Strongly Disagree (or Not Helpful/Detrimental).

then shown the correct answer with an explanation. They then move on to the next review question. Each group discusses each question in a private chatroom. The software is flexible in that it allows the instructor to decide how many students should be in a group and how much time should be allocated for answering individual questions (see Figure 1).

The target MOOC was the Fall 2013 offering of edX's CS.169.2x (Software as a Service) ${ }^{1}$. The six-week course is intended for students with an undergraduate computer science level of expertise and consists of 53 lecture sections, 3 graded quizzes, and 2 graded assignments.

The intervention consisted of providing students with a practice quiz which they could opt to take using an interactive chat tool. Unfortunately, although initially the course had 6,503 students enrolled, at the time of our experiments near the end of the course, only a few hundred widely-dispersed students were active, which made forming groups difficult. Nonetheless, we decided to go ahead and see if any synchronous groups would form in order to get an initial qualitative understanding for participants' reaction to the tool and the method. This paper reports on those initial responses.

\section{RESULTS}

One practice session began each hour. 61 students took the practice quiz and completed the survey. Of these, only 16 were successfully placed in a group of 2 or 3 discussants; six respondents were placed in groups of 3 , and 10 were in groups of 2. (More groups were not formed because not enough students arrived at the same time for the same practice session; a large MOOC with thousands of students should have a higher grouping success rate.) The focus of this report is on the experiences of those students who did have a discussion with others using the chat tool.

Table 1 shows the results of the post-study survey, indicating overall positive responses to the approach. In response to "Other students helped me learn during the discussion," one student wrote "Yes, by having to explain my answers to the other students it forced me to think more deeply about the question," which is one of the central tenets behind collaborative learning. In terms of group size, 6 out of 10 of those in groups of size 2 indicated they wanted more people in the discussion where as everyone placed in a group of size 3 indicated this was the right size for the discussion, again reflecting results from the peer learning literature that dyads do not lend themselves to good discussions.

\footnotetext{
${ }^{1}$ https://www.edx.org/course/uc-berkeleyx/

uc-berkeleyx-cs-169-2x-software-service-1005
}

The first survey question was an open-ended one asking "Do you have any feedback about your experience using this discussion tool? What worked well and what can be improved?" The students expressed general satisfaction. one student commented "It was my first time to use this. I think that overall it is a great tool. We were able to have some brief discussion and it probably is the closest thing that we can get to being the same activity that is in the course." Another wrote "That is very interesting, useful and fun Cool." A third wrote "It's really cool, and make learning more interactive!!!" These comments suggest that students in an online course are quite positive about this approach, and if the synchronization issues can be solved, small coordinated group chats may successfully lead to better learning and retention as has been found widely in the peer learning literature.

\section{CONCLUSIONS}

We have developed an interface and a method to form small ad hoc groups in MOOCs. We've taken first steps in understanding how this interface can guide student discussion in groups, but much work remains to be done. Our next step will be to introduce the method into several large MOOCs, and fully integrate it into every phase of the course. We plan to use it for tests of understanding, as practice quizzes, as study guides, and for other learning activities.

Acknowledgements This material is based upon work supported by the National Science Foundation Grant No. IIS 1149799 and a Google Social Interactions Research Award.

\section{REFERENCES}

1. Deslauriers, L., Schelew, E., and Wieman, C. Improved learning in a large-enrollment physics class. Science 332, 6031 (2011), 862-864.

2. Johnson, D. W., Johnson, R. T., and Smith, K. A. Active learning: Cooperation in the college classroom. Interaction Book Company Edina, MN, 1991.

3. Lasecki, W. S., Murray, K. I., White, S., Miller, R. C., and Bigham, J. P. Real-time crowd control of existing interfaces. In Proceedings ACM UIST (2011).

4. Lord, T. R. Comparing traditional and constructivist teaching in college biology. Innovative Higher Education 21, 3 (1997), 197-217.

5. Millis, B. J., and Cottell, P. G. Cooperative learning for higher education faculty. Oryx Press, 1998.

6. Smith, M. K., Wood, W. B., Adams, W. K., Wieman, C., Knight, J. K., Guild, N., and Su, T. T. Why peer discussion improves student performance on in-class concept questions. Science 323, 5910 (2009), 122-124.

7. Springer, L., Stanne, M. E., and Donovan, S. S. Effects of small-group learning on undergraduates in science, mathematics, engineering, and technology: A meta-analysis. Review of Educational Research 69, 1 (1999), 21-51.

8. Walther, J. B. Interpersonal effects in computer-mediated interaction a relational perspective. Communication Research 19, 1 (1992), 52-90. 